\title{
Dietary guild structure of the fish community in the Northeast United States continental shelf ecosystem
}

\author{
Lance P. Garrison*, Jason S. Link \\ National Marine Fisheries Service, Northeast Fisheries Science Center, 166 Water St., Woods Hole, \\ Massachusetts 02543, USA
}

\begin{abstract}
Trophic guild analysis identifies groups of species that use similar resources within a community. We evaluated the trophic guild structure in an assemblage of 40 fish species in the Northeast United States shelf ecosystem using a 25 yr database of food habits. We explicitly accounted for ontogenetic diet shifts by separating predator species into size classes. There were 14 significant trophic guilds. These distinguished predators based upon prey size and location in the water column (i.e., benthic to pelagic feeding). Ontogenetic diet shifts were important in guild structure, particularly within dominant piscivores. The mean dietary overlap both between and within guilds was notably lower than in other fish communities due to the broad spatial and temporal scale of the study, the diversity of prey types consumed, and the generalist nature of predators in this system. The guild concept is a useful framework to simplify highly connected, complex ecosystems like the Northeast US continental shelf and identify ecologically similar functional units.
\end{abstract}

KEY WORDS: Community structure $\cdot$ Fisheries $\cdot$ Feeding ecology $\cdot$ Ontogeny $\cdot$ Resource partitioning Trophic groups

Resale or republication not permitted without written consent of the publisher

\section{INTRODUCTION}

Root (1967) formulated the original definition of a guild as 'a group of species that exploit the same class of environmental resources in a similar way' and explicitly focused on classifying species based upon their functional role in a community without regard to taxonomy. Resource partitioning among community members is frequently attributed to competitive interactions (Root 1967, Schoener 1974, MacNally 1983, Ross 1986), and the interactions within guilds are assumed to be stronger than those between members of different guilds (Pianka 1980). The guild has been more recently utilized to simplify the structure and dynamics of complex ecosystems regardless of the mechanism generating resource partitioning. Guild members play similar functional roles within ecosystems, and functional classifications may be used to examine the flow of energy and biomass within food webs (reviewed in Hawkins \& MacMahon 1989).

*E-mail: lance.garrison@noaa.gov
Guilds have been defined across multiple gradients including spatial and temporal habitat utilization patterns, diet preferences, and physiological characteristics (Austen et al. 1994). Food resources have received by far the most attention (Simberloff \& Dayan 1991), and trophic guilds have been frequently examined in fish communities (e.g., Ploskey \& Jenkins 1982, Schlosser 1982, Ross 1986, Bayley 1988, Munoz \& Ojeda 1998). In a global survey of studies examining resource partitioning in fish assemblages, trophic gradients were generally most important, particularly in marine systems (Ross 1986).

Studies of resource overlap and guild structure have generally ignored size structure within species (Werner \& Gilliam 1984, Munoz \& Ojeda 1998, Piet et al. 1999). However, fish body sizes may span 4 orders of magnitude across life history, and this broad size range is accompanied by changes in resource use (Werner \& Gilliam 1984). Size-based changes in diet frequently take the form of discrete shifts associated with predator morphology and/or habitat (Werner \& Gilliam 1984, Ross 1986, Olson 1996, Munoz \& Ojeda 
1998, Piet et al. 1999). Therefore, different size-classes of a species may play functionally different ecological roles, may be members of different guilds, and, as a result, intraspecific resource overlap may be lower than interspecific overlap (Polis 1984, Munoz \& Ojeda 1998, Piet et al. 1999). Ignoring size-based changes in resource use artificially increases estimated resource overlap and the perceived interaction between species (Piet et al. 1999).

In the Northeast US continental shelf fish community, fishery exploitation has driven major changes in community structure over the last 3 decades. During the 1970s and 1980s, fishery removals severely reduced groundfish stocks while the biomass of lessexploited elasmobranchs, particularly spiny dogfish, began to rise (Fogarty \& Murawski 1998, NEFSC 1998). Since the mid-1980s, pelagic stocks (e.g., Atlantic herring and Atlantic mackerel) have dramatically increased. Relative to levels prior to 1970, the biomass index of gadids and flatfish has declined by roughly $70 \%$, that of elasmobranchs has increased by roughly $200 \%$, and that of pelagic species has increased by approximately $150 \%$ (NEFSC 1998).

These changes in species composition are associated with both direct and indirect effects of fishing pressure. In particular, increases in historically underexploited species are frequently attributed to potential predatory and/or competitive release following the removal of formerly dominant gadids and flounders by the fishery (Fogarty \& Murawski 1998). Dietary overlap between species has been explicitly cited as a potential source of competitive interactions that impact population dynamics (Fogarty \& Murawski 1998). We define trophic guilds within the Northeast shelf fish community to characterize trophic interactions, explicitly accounting for ontogenetic diet shifts. We assess the potential for competition based upon patterns of resource use and explore the utility of the guild concept as a tool for understanding and managing this complex ecosystem.

\section{METHODS}

Data sources. The data for this study were drawn from seasonal bottom trawl surveys conducted by the Northeast Fisheries Science Center (NEFSC) between 1973 and 1997. The surveys employ a stratified random sampling design with strata defined by depth and latitude. Sample depths ranged between 8 and $400 \mathrm{~m}$. Sample stations were defined by $2.5^{\prime}$ latitude by $2^{\prime}$ longitude rectangular units that were randomly selected within strata. Between 350 and 400 stations on the continental shelf between Cape Hatteras, North Carolina and Nova Scotia (Fig. 1) were sampled during each seasonal survey of approximately 4 to $6 \mathrm{wk}$ in duration (NEFC 1988). At each station, a No. 36 Yankee (or similar) bottom trawl was deployed for $30 \mathrm{~min}$ and towed at a speed of $6.5 \mathrm{~km} \mathrm{~h}^{-1}$. Tows with non-representative sampling due to gear damage or logistical considerations were removed prior to analyses. For each tow, catch (in both mass and numbers) at length $(1 \mathrm{~cm}$ length classes) was recorded for all species with subsampling of catch as appropriate for large samples. Details of the survey sampling design, execution, and efficiency are available in Azarovitz (1981) and NEFC (1988).

Food habits sampling was conducted on selected species during survey cruises from 1973 to the present. The majority of the food habits data was collected during spring and autumn surveys with reduced temporal and spatial coverage during winter and summer (NEFSC 1999). Stomachs of individual fish representative of captured size classes were examined. Prior to 1981, stomach contents were preserved and returned to the laboratory for identification. Total stomach content mass and the mass of each prey was measured to the nearest $0.1 \mathrm{~g}$. Since 1981, stomach contents have been examined at sea. The total volume $\left(\mathrm{cm}^{3}\right)$ of stomach contents was measured and the proportion of stomach contents comprised by each prey type was estimated. Details of the food habits sampling methodology are available in Bowman \& Michaels (1984) and NEFSC (1999).

During the early 1980s, prey composition was estimated by both weight and volume. To reconcile the

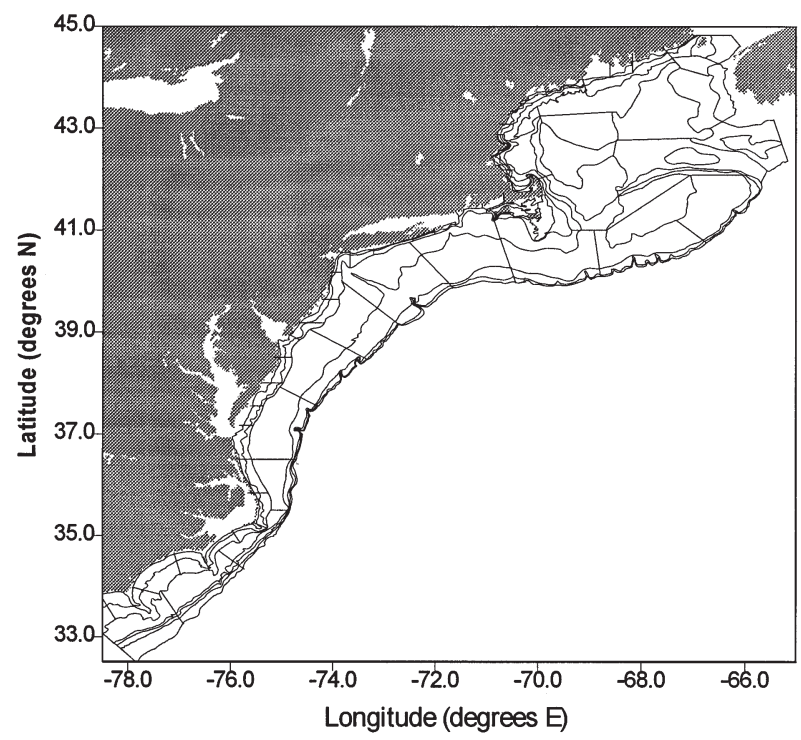

Fig. 1. Sampling area on the Northeast US continental shelf showing strata employed in the Northeast Fisheries Science Center bottom trawl survey 
different sampling methods, we performed a linear regression of prey weight versus prey volume within the same stomachs both for individual predator species and across all available stomachs (total $\mathrm{N}=10806$ stomachs). The regression model was highly significant $\left(p<0.0001, r^{2}>0.90\right)$ for both the overall model and models for each species. Based upon this analysis, prey weights (g) from the 1973 to 1980 time period were divided by 1.1 to convert them to volumes $\left(\mathrm{cm}^{3}\right)$ for continuity within the time series.

Stomach contents during both periods were identified to the lowest possible taxonomic level. Since stomach contents were identified in the laboratory during the earlier time period (1973 to 1980), the taxonomic resolution of invertebrate prey is generally higher in these samples than during the later period (1981 to 1997). In the current study, invertebrate prey were grouped by family or order to reduce the differences in taxonomic resolution between the 2 time periods. Common fish and squid prey were considered at the genus level while less important fish prey were grouped by family or order. Rarely observed fish families were grouped into an 'other fish' category. The resulting prey classification contained 52 categories (Table 1).

Data from 40 predator species (Table 2) and approximately 107000 stomachs were included in the current analysis. We included numerically dominant, commercially valuable, and ecologically important species in the Northwest Atlantic. Predator species were divided into length categories to account for known ontogenetic shifts in diet. Historical data summaries (Bowman \& Michaels 1984) were examined to identify shifts in diet with size for all species. Only those predator categories with adequate food habits sampling ( $>20$ stomachs sampled) were included in the analysis (85 predator categories, Table 2).

Dietary overlap and trophic guild analysis. A matrix of the Schoener (1970) similarity index (Eq. 1) was used to assess the dietary overlap, $D_{i j}$, between predator pairs:

$$
D_{i j}=1-0.5\left(\sum\left|p_{i k}-p_{j k}\right|\right)
$$

where $p_{i k}=$ mean proportional volume of prey type $k$ in predator $i$ and $p_{j k}=$ mean proportional volume of prey type $k$ in predator $j$. Hierarchical agglomerative clustering methods were used to identify groups of species with common diets using the Schoener index combined with group average clustering (Pielou 1984). The dendrogram was not sensitive to changes in the clustering algorithm.

The randomization method described by Jaksic \& Medel (1990) was used to identify 'significant' dietary guilds in the resulting cluster diagram. The method employs a bootstrap randomization of the raw data (predator $\times$ prey matrix) to generate a distribution of
Table 1. Prey categories used in the diet analysis

\begin{tabular}{|c|c|}
\hline Scientific name & Common name \\
\hline Ammodytes spp. & Sand lance \\
\hline Amphipoda & Unclassified amphipods \\
\hline Anthozoa & Anemones \\
\hline Animal remains & Unidentified animal remains \\
\hline Bivalvia & Bivalves \\
\hline Cancridae & Cancer crabs \\
\hline Cephalopoda & Unclassified cephalopods \\
\hline Clupeidae & Herrings \\
\hline Clupea harengus & Atlantic herring \\
\hline Cnidarians & Jellies and hydroids \\
\hline Cottidae & Sculpins \\
\hline Crangonidae & Crangonid shrimps \\
\hline Crustacean shrimp & Unclassified shrimp \\
\hline Crustacea & Unclassified crustaceans \\
\hline Ctenophora & Comb-jellies \\
\hline Decapoda crabs & Decapod crabs \\
\hline Decapoda shrimp & Decapod shrimp \\
\hline Echinodermata & Unclassified echinoderms \\
\hline Engraulidae & Anchovies \\
\hline Euphausiidae & Euphausiid shrimp, krill \\
\hline Fish eggs & Fish eggs \\
\hline Fish larvae & Fish larvae \\
\hline Gadiformes & Gadid fish \\
\hline Gammaridae & Gammarid amphipods \\
\hline Gastropoda & Snails \\
\hline Holothuroidea & Sea cucumbers \\
\hline Hydrozoa & Hydroids \\
\hline Hyperiidae & Hyperiid amphipods \\
\hline Illex spp. & Illex squid \\
\hline Isopoda & Isopods \\
\hline Lepophidium profundorum & Fawn cusk-eel \\
\hline Loligo spp. & Loligo squid \\
\hline Macrozoarces americanus & Ocean pout \\
\hline Merluccius bilinearis & Silver hake \\
\hline Miscellaneous & Inorganic material \\
\hline Mollusca & Unclassified molluscs \\
\hline Mysidacea & Mysid shrimps \\
\hline Ophiuroidea & Brittle stars \\
\hline Other hakes & Red, white, and spotted hake \\
\hline Other & Unidentified organic material \\
\hline Other fish & Other fish \\
\hline Other invertebrates & Other invertebrates \\
\hline Paguroidea & Hermit crabs \\
\hline Pandalidae & Pandalid shrimps \\
\hline Peprilus triacanthus & Butterfish \\
\hline Pleuronectiformes & Flatfish \\
\hline Polychaeta & Polychaete worms \\
\hline Rajiformes & Rays, skates \\
\hline Scombridae & Mackerels \\
\hline Unidentified fish & Unidentified fish remains \\
\hline Worms & Assorted worms \\
\hline Zooplankton & Zooplankton \\
\hline
\end{tabular}

overlap indices reflecting the null hypothesis of no consistent diet composition within predators. We employed a randomization scheme whereby zeros in the predator-prey matrix were retained in their origi- 
Table 2. Predator species and size classes used in the diet analysis

\begin{tabular}{|c|c|c|c|c|c|}
\hline \multirow[t]{2}{*}{ Scientific name } & \multirow[t]{2}{*}{ Common name } & \multicolumn{4}{|c|}{ — Size categories $(\mathrm{cm})-$} \\
\hline & & Small & Medium & Large & Extra large \\
\hline Mustelus canis & Smooth dogfish & & $41-60$ & $61-80$ & \\
\hline Squalus acanthias & Spiny dogfish & $10-40$ & $41-60$ & $61-80$ & \\
\hline Raja ocellata & Winter skate & $10-30$ & $31-60$ & $61-80$ & $>80$ \\
\hline Raja erinacea & Little skate & $10-30$ & $31-60$ & & \\
\hline Raja senta & Smooth skate & & $31-60$ & & \\
\hline Raja radiata & Thorny skate & $10-30$ & $31-60$ & $61-80$ & $>80$ \\
\hline Clupea harengus & Atlantic herring & $10-20$ & $21-30$ & & \\
\hline Alosa pseudoharengus & Alewife & & $21-30$ & & \\
\hline Merluccius bilinearis & Silver hake & $10-20$ & $21-40$ & $>40$ & \\
\hline Gadus morhua & Atlantic cod & $10-20$ & $21-50$ & $51-80$ & $>80$ \\
\hline Melanogrammus aeglefinus & Haddock & $10-20$ & $21-50$ & $51-80$ & \\
\hline Pollachius virens & Pollock & $10-20$ & $21-50$ & $51-80$ & $>80$ \\
\hline Urophycis tenuis & White hake & $10-20$ & $21-40$ & $>40$ & \\
\hline Urophycis chuss & Red hake & $10-20$ & $21-40$ & $>40$ & \\
\hline Urophycis regia & Spotted hake & $10-20$ & $21-40$ & & \\
\hline Hippoglossoides platessoides & American plaice & $10-20$ & $21-40$ & $41-70$ & \\
\hline Paralichthys dentatus & Summer flounder & & $21-40$ & $41-70$ & \\
\hline Paralichthys oblongus & Fourspot flounder & $10-20$ & $21-40$ & & \\
\hline Limanda ferruginea & Yellowtail flounder & $10-20$ & $21-40$ & $41-70$ & \\
\hline Pseudopleuronectes americanus & Winter flounder & $10-20$ & $21-40$ & $41-70$ & \\
\hline Glyptocephalus cynoglossus & Witch flounder & & $21-40$ & $41-70$ & \\
\hline Scophthalmus aquosus & Windowpane & $10-20$ & $21-40$ & & \\
\hline Citharichthys arctifrons & Gulfstream flounder & $10-20$ & & & \\
\hline Scomber scombrus & Atlantic mackerel & $10-20$ & $21-35$ & $>35$ & \\
\hline Peprilus triacanthus & Butterfish & $10-20$ & & & \\
\hline Pomatomus saltatrix & Bluefish & $10-30$ & $31-70$ & $>70$ & \\
\hline Micropogon undulatus & Atlantic croaker & $10-25$ & $26-50$ & & \\
\hline Centropristis striata & Black sea bass & $10-25$ & $26-50$ & & \\
\hline Stenotomus chrysops & Scup & & $26-50$ & & \\
\hline Cynoscion regalis & Weakfish & $10-25$ & $26-50$ & & \\
\hline Sebastes fasciatus & Redfish & & $26-50$ & & \\
\hline Myoxocephalus octodecemspinosus & Longhorn sculpin & $10-25$ & $26-50$ & & \\
\hline Hemitripterus americanus & Sea raven & $10-25$ & $26-50$ & & \\
\hline Ammodytes dubius & Sand lance & & $11-25$ & & \\
\hline Macrozoarces americanus & Ocean pout & & & $>60$ & \\
\hline Lepophidium profundorum & Fawn cusk-eel & & & $>60$ & \\
\hline Lophius americanus & Goosefish & & & $>60$ & \\
\hline Rhizoprionodon terraenovae & Atlantic sharpnose shark & & & $>60$ & \\
\hline Illex illecebrosus & Northern shortfin squid & & & $>30$ & \\
\hline Loligo pealeii & Longfin squid & & & $>30$ & \\
\hline
\end{tabular}

nal positions (Lawlor 1980, Winemiller \& Pianka 1990). The algorithm randomly rearranges the proportions (e.g., $p_{i k}$ in Eq. 1) of prey types occurring in the diet of a given predator. This randomization retains structure in the original matrix and is therefore a conservative null model with which to assess significant guilds (Jaksic \& Medel 1990)

The randomization was repeated 250 times (Jaksic \& Medel 1990), and the bootstrap distribution of calculated diet overlaps was examined to find the similarity level greater than $95 \%$ of values under the null hypothesis. This similarity level was used as an objective benchmark to determine significant dietary guilds (Jaksic \& Medel 1990).

\section{RESULTS}

The bootstrap randomization indicated that a similarity level greater than 0.34 was unlikely to occur by chance. In the cluster diagram, 14 groups clustered well above this level (range of similarity index for sub-groups 0.39 to 0.73 , Fig. 2) and were therefore considered 'significant' dietary guilds. These guilds were broadly categorized into 6 trophic groups (Fig. 2), emphasizing similarities in diet at very broad taxonomic levels (e.g., piscivores). Within these groups, the trophic guilds reflect different utilization of specific prey types. For example, Guild 6b (Fig. 2) consumed primarily engraulids in contrast to other guilds in the piscivore group. 


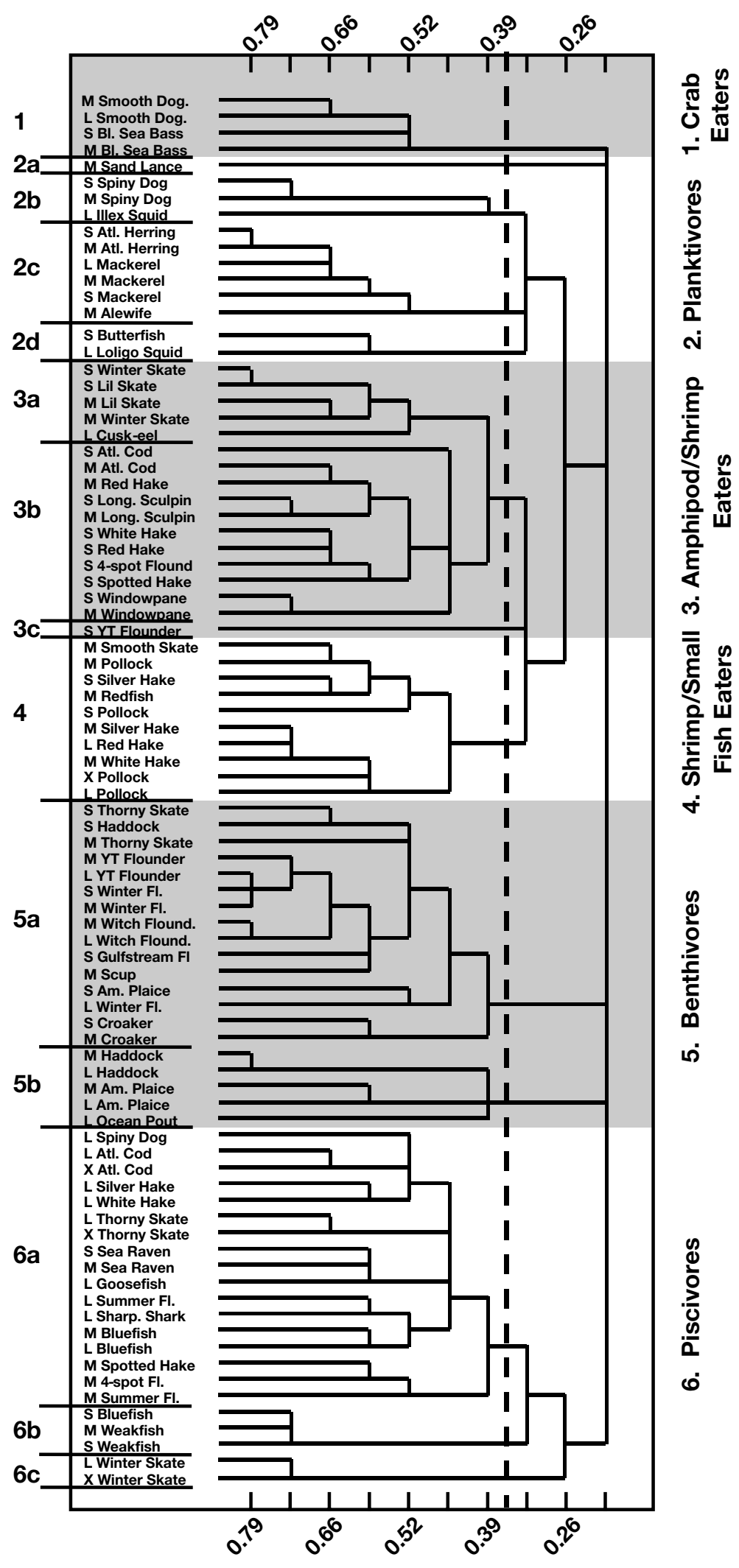

Similarity Level
The first guild clustered at a similarity level of 0.52 and included smooth dogfish and black sea bass (Fig. 2). A high proportion of crabs in their diets distinguishes these species. Cancer crabs (family Cancridae) and unclassified decapod crabs together accounted for $57 \%$ of the diets of these species (Fig. 3). Zooplankton and bivalves were also important prey items.

There were 4 guilds of planktivores and small pelagic predators (Fig. 2). Sand lance was separated from other planktivores because over $80 \%$ of its diet was zooplankton (Fig. 4). Small and medium spiny dogfish and shortfin squid formed a cluster at the $39 \%$ similarity level and consumed primarily cephalopods and unidentified fish. Ctenophores were also an important component of small spiny dogfish diets (Fig. 4). Atlantic herring and mackerel consumed a diverse suite of prey including zooplankton, euphausiids, and shrimp (Fig. 4). Finally, butterfish and longfin squid had similar diets based upon the high proportion of unidentified animal remains in these predators (Fig. 4).

The third major group included 3 guilds of predators with diverse diets including both small benthic prey and pelagic shrimp (Fig. 2). Small winter and little skates clustered together and had diets dominated by amphipods and polychaetes but also included pelagic organisms such as shrimps and zooplankton (Fig. 5). The second guild in this group included small demersal predators such as small Atlantic cod, longhorn sculpin (all sizes), and small hakes. These predators consumed a broad range of prey including a number of shrimp taxa, amphipods, crabs, and unidentified fish (Fig. 5). Finally, small yellowtail flounder was separated from other predators by the high proportion ( $>55 \%$ ) of amphipods in its diet (Fig. 5).

The fourth group included a single guild of predators including medium white hake, large red hake, medium to extra-large pollock, small and medium silver hake, and red-

Fig. 2. Dendrogram showing major predator groups (right side, shading) and statistically significant dietary guilds (left side) as indicated by the bootstrap method of Jaksic \& Medel (1990). Vertical dashed line: similarity level of 0.342 . Groups of species that cluster at a similarity level $>0.342$ are unlikely to have occurred by chance and indicate significant guilds above the $95 \%$ confidence level 
fish (Fig. 2). Shrimp taxa were the dominant dietary component for these predators. Euphausiids, other shrimp, pandalid shrimps, and unclassified decapod shrimps together accounted for $48 \%$ of predator diets in this guild. Small fish prey were also important and included unidentified fish, silver hake, sand lance, and Atlantic herring (Fig. 6).

The fifth group included 2 guilds of predators on benthic invertebrates (Fig. 2). The larger guild included mainly flatfish such as winter flounder, yellowtail flounder, and witch flounder (Fig. 2). These species consumed $43 \%$ polychaetes (Fig. 7). The guild including large haddock and American plaice was distinguished from the flatfish guild by the high proportion of echinoderms in the diet of haddock and plaice. Unclassified echinoderms and ophiuroids accounted for $52 \%$ of the diets of these predators (Fig. 7).

The sixth major group included 3 guilds of piscivores (Fig. 2). The largest guild included a suite of large demersals, large skates, large spiny dogfish, and large hakes (Fig. 2). These species consumed a range of fish taxa including Atlantic herring and other clupeids, silver hake, scombrids, and sand lance. Squid taxa were also important components of the diets of these predators (Fig. 8). Two minor guilds occurred within the piscivores that distinguish predators focusing on single fish taxa. Small bluefish and weakfish form a guild of coastal predators that consumed primarily anchovies (Engraulidae; Fig. 8). Large winter skates were characterized by the high proportion (37\%) of sand lance in their diets (Fig. 8).

\section{DISCUSSION}

The dietary guilds in the Northeast US shelf fish community reflect similarity in the utilization of specific prey categories. Within guilds, 10 to 15 prey taxa

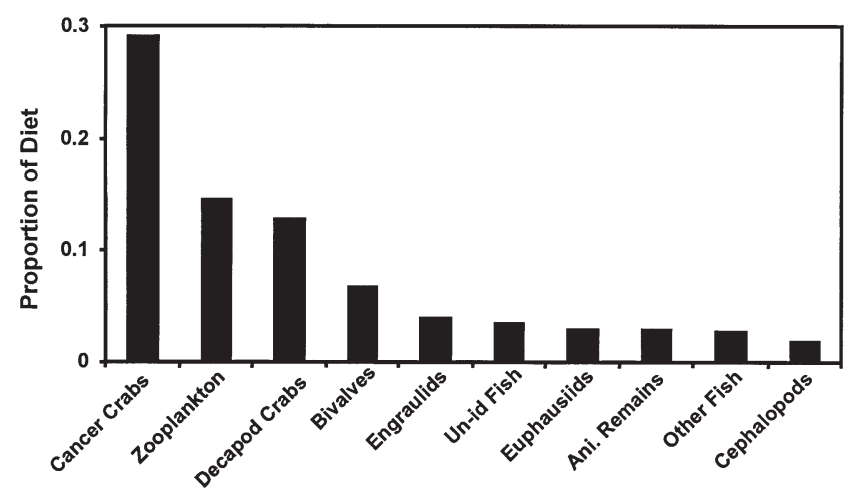

Fig. 3. Mean proportional composition (by volume) of major prey items in Group 1 (Crab eaters, Fig. 2). Bars represent average prey content within guilds. These 10 prey accounted for $81 \%$ of predator diets generally accounted for $>70 \%$ of predator diets and usually $<5$ prey accounted for $>50 \%$ of the diet. A relatively small set of prey taxa distinguishes the observed dietary guild structure.

The general guild structure and levels of dietary overlap in this system are consistent across both temporal and spatial scales. A complimentary analysis to the current study within the Georges Bank region identified similar trophic guilds, similar patterns of size-based shifts in diets, and general stability in the trophic guild structure over the last 3 decades (Garrison \& Link in press). Despite the notable changes in species composition in the Northeast shelf fish community, the patterns of trophic resource use and guild structure are remarkably consistent.

Unidentified fish and unclassified animal remains are important components of the diets of many species. Both prey categories likely include small, soft-bodied prey such as zooplankton, polychaetes, small fish, and small crustaceans that are quickly digested and are therefore difficult to identify, even in fresh stomachs. These categories are especially problematic for butterfish and squids that masticate prey items during ingestion, making identification of stomach contents particularly difficult. Because both unidentified fish and animal remains are common prey across guilds, their effect is to increase diet overlap and reduce the separation between trophic guilds. While the identification problem is a common difficulty encountered in the analysis of stomach contents, the effect on the current analysis is to make the assessment of guild structure more conservative.

The major patterns in trophic resource partitioning in the Northeast shelf fish community are comparable to those observed in other fish communities. Major prey gradients in marine systems typically range from polychaetes to fish prey or small pelagic prey to benthic invertebrates (Ross 1986). These patterns occur in coral reefs, coastal marine systems, deepwater slope

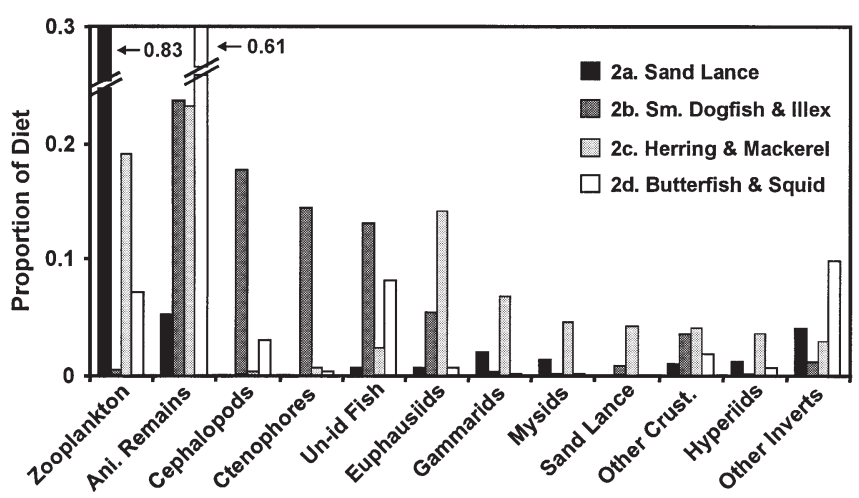

Fig. 4. Mean proportional composition (by volume) of major prey items in Group 2 (Planktivores, Fig. 2). Bars represent average prey content within guilds. These 12 prey account for 81 to $99 \%$ of predator diets 


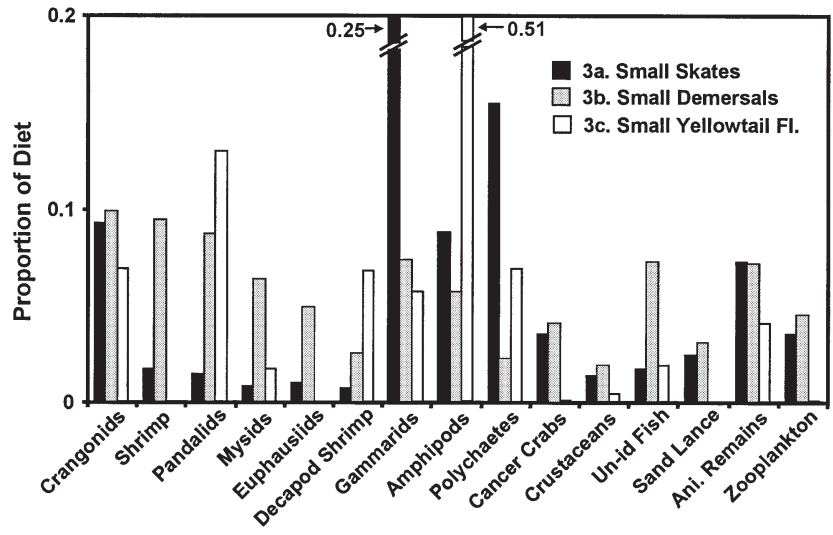

Fig. 5. Mean proportional composition (by volume) of major prey items in Group 3 (Amphipod/Shrimp eaters, Fig. 2). Bars represent average prey content within guilds. These 15 prey account for 84 to $98 \%$ of predator diets

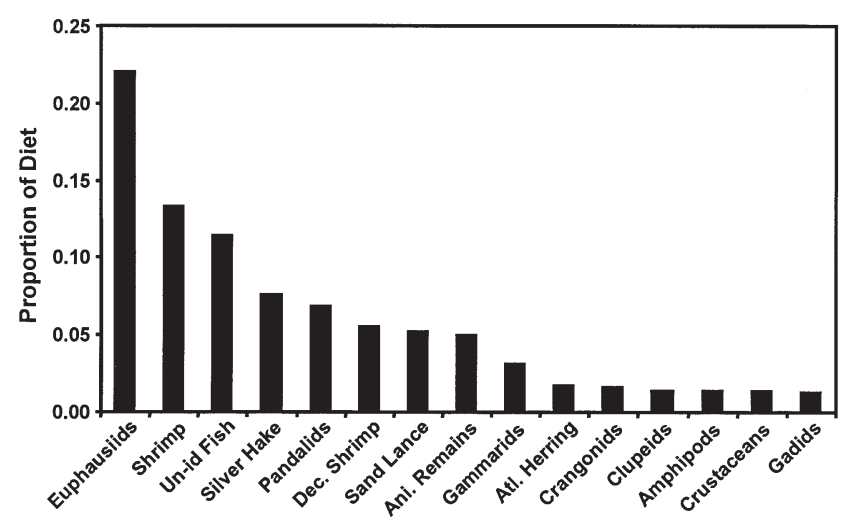

Fig. 6. Mean proportional composition (by volume) of major prey items in Group 4 (Shrimp/Small fish eaters, Fig. 2). Bars represent average prey content within guilds. These 15 prey account for $89 \%$ of predator diets

communities, and Antarctic habitats (Ross 1986). In lakes, major gradients range from insect to fish prey, and in streams, insect predators are separated from herbivores (Ross 1986). All of these systems have 2 major aspects to the partitioning of resources by fish communities that appear to be general organizing factors across ecosystems. The first is a vertical one ranging from benthic to pelagic to surface oriented feeding and reflects predator and/or prey habitat. The second is a prey size gradient related to morphological constraints (e.g., predator gape width, gill raker spacing, body size, swimming speeds) on prey availability. Similar patterns were observed in the Northeast shelf ecosystem with predators feeding on benthic prey (e.g., benthivore guilds and crab predators) separated from those feeding on pelagic prey (e.g., shrimp predator guild and planktivore guilds), and predators feed-

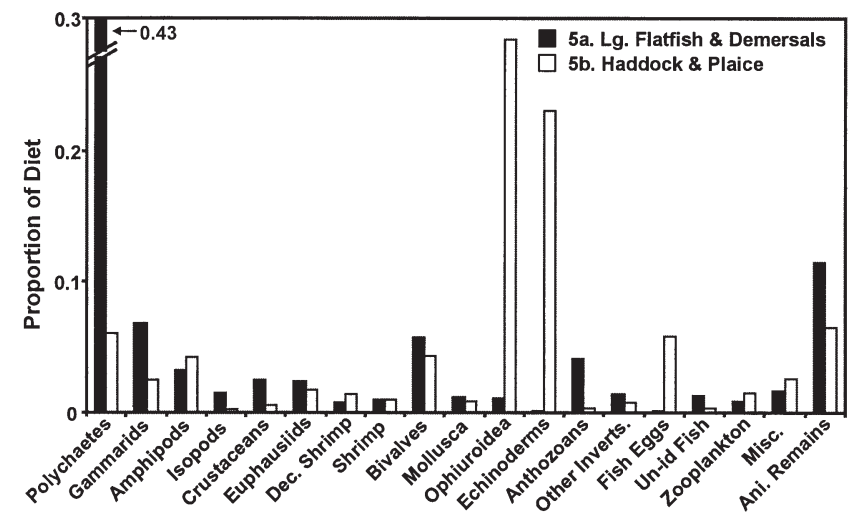

Fig. 7. Mean proportional composition (by volume) of major prey items in Group 5 (Benthivores, Fig. 2). Bars represent average prey content within guilds. These 19 prey account for 90 to $92 \%$ of predator diets

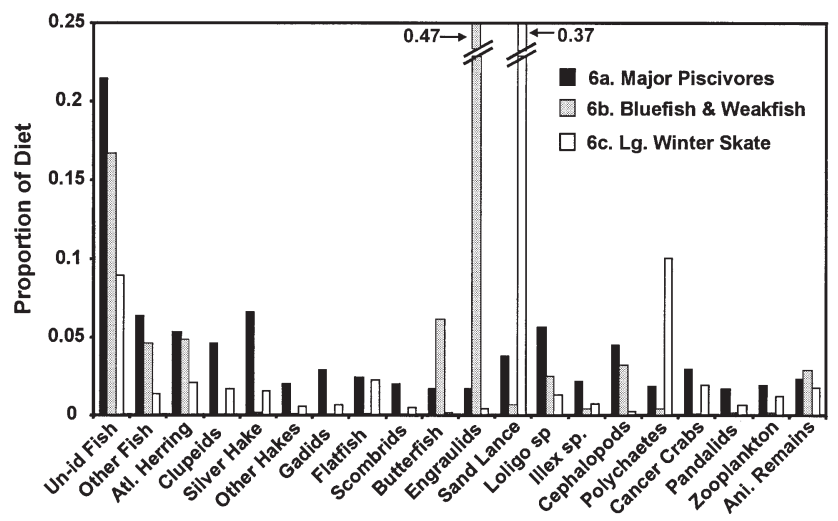

Fig. 8. Mean proportional composition (by volume) of major prey items in Group 6 (Piscivores, Fig. 2). Bars represent average prey content within guilds. These 20 prey account for 75 to $90 \%$ of predator diets

ing on small invertebrate prey (e.g., shrimp predator guilds, benthivore guilds) were distinct from those feeding on large prey (e.g., crab predators, piscivore guilds).

Size-based diet shifts were a common pattern in the Northeast shelf fish community, similar to other fish communities (Werner \& Gilliam 1984, Ross 1986, Olson 1996, Munoz \& Ojeda 1998). There was a notable trend toward increased piscivory with size particularly for spiny dogfish, Atlantic cod, white hake, silver hake, and winter skate. With the exception of spiny dogfish, in the smaller size classes these species were members of either the amphipod/shrimp predators (Guild 3b, Fig. 2) or the shrimp/small fish predators (Guild 4, Fig. 2). Small and medium sized spiny dogfish were planktivorous (Guild 2b, Fig. 2) and consumed ctenophores along with shrimp, squids, and small fish. There 
were more subtle changes in some of the benthivorous species. For example, yellowtail flounder diets were dominated by amphipods at small sizes and changed to polychaetes at large size classes. Haddock also consumed primarily polychaetes in small size classes and echinoderms in larger sizes. In contrast, there was a lack of important diet changes with size in planktivores, many flatfish species, and demersal predators including sea raven and longhorn sculpin.

Changes in either morphology or habitat across life history can contribute to diet shifts (Werner \& Gilliam 1984). In the case of piscivores, the range of available prey generally increases with predator size related to increases in predator gape width, swimming speed, and visual acuity (reviewed in Juanes 1994). Habitat changes through life history can also contribute to changes in diet associated with differential prey availability (Werner \& Hall 1988, Osenberg et al. 1992). It is likely that changes in both habitat and size contribute to the ontogenetic diet shifts observed in the Northeast shelf fish community. The current analysis averages across broad spatial and temporal scales; however, more detailed analyses could identify spatial and temporal patterns in diets related to these factors. Regardless of mechanism, it is clear that size shifts in diets occur in many of the dominant species in this community, and this has important implications for both trophic dynamics and fisheries management.

The mean index of dietary overlap across guilds in the Northeast shelf fish community was 0.23 and was typically $\sim 0.50$ within most guilds (Fig. 2). In general, the mean dietary overlap both between and within guilds in this system is considerably lower than that observed in other marine fish communities. Mean dietary overlap across guilds in systems including seagrass habitats (Livingston 1982), coral reefs (Gladfelter \& Johnson 1983), and streams (Pausey et al. 1995) was on the order of 0.3 to 0.5 compared to 0.23 in the Northeast shelf ecosystem. The reduced dietary overlap we observed results from several characteristics of this community. First, the current study encompasses larger temporal and spatial scales than other analyses. As a result, the range of habitats is broader and the number of potential predators and prey is higher, reducing the average dietary overlap. Second, we have accounted explicitly for ontogenetic shifts in diets, which are generally not included in other analyses.

The magnitude of dietary overlap within guilds in the Northeast shelf ecosystem is generally lower than that in other marine systems. In the current study, the overlap value identifying most guilds was on the order of $0.5 \%$. In the diverse systems cited above, overlap values within guilds generally ranged from 0.6 to 0.8 . The diverse range of prey types and the generalist nature of the predators tend to reduce the dietary over- lap between species. The range of prey types consumed by each predator is large, there is generally little mutual reliance on a single prey type between any given pair of predators, and the potential for strong dietary overlap is reduced. The exception is those predators that are specialists. For example, the dietary overlap within the coastal piscivores guild (6b, Fig. 2) was very high, reflecting specialization on a particular prey (i.e., anchovies).

Competitive release associated with dietary overlap has been proposed as a mechanism for the observed shifts in community structure in the Northeast US shelf fish community (Fogarty \& Murawski 1998). However, the patterns of resource use we observed suggest that the potential for competition is low. For exploitative competition to occur as an active mechanism influencing population dynamics there must be the potential for significant overlap in resource use and resources must be limiting to populations (MacNally 1983). Given the broad diets of the fish in this ecosystem and the generally low dietary overlap relative to other systems, the potential for strong mutual reliance on a given prey type is reduced. The ontogenetic shifts in diets will further reduce mutual reliance on a given prey and the competitive interactions between species as noted in other systems (Piet et al. 1999). In addition, predators in this system, particularly piscivores, generally switch among a suite of available prey, largely dependant upon prey abundance (Overholtz et al. 1999), and it is unlikely that multiple prey will be simultaneously limiting in this highly productive ecosystem (Sissenwine et al. 1984). Finally, there is persistent spatial partitioning within the fish community, including among species within the same trophic guild, at both regional and sub-regional scales (Gabriel 1992). Therefore, high similarity in resource use resulting in competitive exclusion appears to be unlikely in this system. We therefore hypothesize that exploitative competition for food resources is not an important factor structuring the fish community on the Northeast US continental shelf.

Fisheries management has traditionally taken a single-species approach designed to maximize the long-term sustainable yield of desirable species. However, in recent years there has been an increased recognition of community-wide interactions that regulate the dynamics of exploited populations (Larkin 1996, Jennings \& Kaiser 1998, NRC 1999). Taking account of 'ecosystem considerations' in fishery management requires improved understanding of fish community ecology (Larkin 1996, Jennings \& Kaiser 1998). 'Macro-descriptors' of community function and interspecies interactions are potentially a valuable tool to simplify these complex ecosystems (Orians 1980, Winemiller \& Pianka 1990, Austen et al. 1994). The 
focus on similar functional roles of guild members has utility for defining 'ecological units' within multispecies models. The food web of the Northeast shelf is extremely complex and highly connected, with a large number of trophic interactions between species (Link 1999). It is helpful to reduce this to an ecologically meaningful yet computationally tractable level of complexity. Identifying trophic guilds is a useful first step for defining groups of functionally similar species.

Acknowledgements. We acknowledge the foresight and diligence of the present and past staff of the NEFSC in the planning and execution of the bottom trawl surveys. We thank the members of the Food Web Dynamics program, who were responsible for the collection, auditing, and management of the food habits database. In particular, we recognize the contributions of Cheryl Milliken, Karen Bolles, Richard Yetter, Brian Kaminer, Nancy McHugh, Rodney Rountree, Mike Fogarty, and Frank Almeida. Frank Almeida, Mark Terceiro, and Wendy Gabriel and 3 anonymous reviewers provided thorough and helpful reviews of the manuscript. L.P.G. was supported by a National Research Council post-doctoral research associateship at the NEFSC.

\section{LITERATURE CITED}

Austen DJ, Bayley PB, Menzel BW (1994) Importance of the guild concept to fisheries research and management. Fisheries 19(6):12-19

Azarovitz TR (1981) A brief historical review of the Woods Hole Laboratory trawl survey time series. In: Doubleday WG, Rivard D (eds) Bottom trawl surveys. Can Spec Publ Fish Aquat Sci 58:62-67

Bayley PB (1988) Factors affecting growth rates of young tropical flood plain fishes: seasonality and density dependence. Environ Biol Fish 21:127-142

Bowman RE, Michaels WL (1984) Food of seventeen species of Northwest Atlantic fish. NOAA Tech Memo, NOAA, Washington, DC, NMFS-F/NEC-28

Fogarty MJ, Murawski SA (1998) Large-scale disturbance and the structure of marine systems: fishery impacts on Georges Bank. Ecol Appl 8(1):S6-S22

Gabriel WB (1992) Persistence of demersal fish assemblages between Cape Hatteras and Nova Scotia, Northwest Atlantic. J Northwest Atl Fish Sci 14: 29-46

Garrison LP, Link JS (in press) Fishing effects on spatial distribution and trophic guild structure of the fish community in the Georges Bank region. ICES J Mar Sci 57

Gladfelter WB, Johnson WS (1983) Feeding niche separation in a guild of tropical reef fishes (Holocentridae). Ecology 64:552-563

Hawkins CP, MacMahon JA (1989) Guilds: the multiple meanings of a concept. Annu Rev Entomol 34:423-451

Jaksic FM, Medel RG (1990) Objective recognition of guilds: testing for statistically significant species clusters. Oecologia 82:87-92

Jennings S, Kaiser MJ (1998) The effects of fishing on marine ecosystems. Adv Mar Biol 34:203-352

Juanes $F$ (1994) What determines prey size selectivity in piscivorous fishes? In: Stouder DJ, Fresh KL, Feller RJ (eds) Theory and application in fish feeding ecology. University of South Carolina Press, Columbia
Larkin PA (1996) Principles of ecosystem management of fisheries. Rev Fish Biol Fish 6:139-164

Lawlor LR (1980) Structure and stability in natural and randomly constructed competitive communities. Am Nat 116 : 394-408

Link JS (1999) (Re)constructing food webs and managing fisheries. In: Ecosystem approaches for Fisheries management. University of Alaska Sea Grant, AK-SG-99-01, Fairbanks, p 571-589

Livingston RJ (1982) Trophic organization of fishes in a coastal seagrass system. Mar Ecol Prog Ser 7:1-12

MacNally RC (1983) On assessing the significance of interspecific competition to guild structure. Ecology 64: $1646-1652$

Munoz AA, Ojeda FP (1998) Guild structure of carnivorous intertidal fishes of the Chilean coast: implications of ontogenetic dietary shifts. Oecologia 114:563-573

National Research Council (1999) Sustaining marine fisheries. National Academy Press, Washington, DC

Northeast Fisheries Center (1988) An evaluation of the bottom trawl survey program of the Northeast Fisheries Center. NOAA Tech Memo, NOAA, Washington, DC, NMFSF/NEC-52

Northeast Fisheries Science Center (1998) Status of the fishery resources off the northeastern United States for 1998, NOAA, Washington, DC. NOAA Tech Memo, NOAA, Washington, DC, NMFS-NE-115

Northeast Fisheries Science Center (1999) Food Web Dynamics Program. National Marine Fisheries Service, Woods Hole, MA (accessed: March 1999); available at http://www.nefsc.nmfs.gov/pbio/fwdp

Olson MH (1996) Ontogenetic niche shifts in largemouth bass: variability and consequences for first year growth. Ecology 77:179-190

Orians GH (1980) Micro and macro in ecological theory. Bioscience 30:79

Osenberg CW, Mittelbach GG, Wainwright PC (1992) Twostage life histories in fish: the interaction between juvenile competition and adult performance. Ecology 73:255-267

Overholtz WJ, Link JS, Suslowicz LE (1999) Consumption and harvest of pelagic fish and squid in the Gulf of MaineGeorges Bank ecosystem: implications for fisheries management. In: Ecosystem approaches for Fisheries management. University of Alaska Sea Grant, AK-SG-99-01, Fairbanks, p 163-187

Pausey BJ, Martin GR, Arthington AH (1995) The feeding ecology of freshwater fishes in two rivers of the Australian wet tropics. Environ Biol Fish 43:85-103

Pianka ER (1980) Guild structure in desert lizards. Oikos 35: 194-201

Pielou EC (1984) The interpretation of ecological data: a primer on classification and ordination. John Wiley and Sons, New York

Piet GJ, Pet JS, Guruge WAHP, Vijverberg J, Van Densen WLT (1999) Resource partitioning along three niche dimensions in a size-structured tropical fish assemblage. Can J Fish Aquat Sci 56:1241-1254

Ploskey GR, Jenkins RM (1982) Biomass model of reservoir fish and fish-food interactions, with implications for management. N Am J Fish Manage 2:105-121

Polis GA (1984) Age structure component of niche width and intraspecific resource partitioning: can age groups function as ecological species? Am Nat 123:541-546

Root RB (1967) The niche exploitation pattern of the blue-gray gnatcatcher. Ecol Monogr 37:317-350

Ross ST (1986) Resource partitioning in fish assemblages: a review of field studies. Copeia 1986(2):352-368 
Schlosser IJ (1982) Trophic structure, reproductive success, and growth rate of fishes in a natural and modified headwater stream. Can J Fish Aquat Sci 39:968-978

Schoener TW (1970) Nonsynchronus spatial overlap of lizards in patchy habitats. Ecology 51:408-418

Schoener TW (1974) Resource partitioning in ecological communities. Science 185:27-39

Simberloff D, Dayan T (1991) The guild concept and the structure of ecological communities. Annu Rev Ecol Syst 22: 115-143

Sissenwine MP, Cohen EB, Grosslein MD (1984) Structure of

Editorial responsibility: Kenneth Sherman (Contributing Editor), Narragansett, Rhode Island, USA the Georges Bank ecosystem. Rapp P-V Reun Con Int Explor Mer 183:243-254

Werner EE, Gilliam JF (1984) The ontogenetic niche and species interactions in size-structured populations. Annu Rev Ecol Syst 15:393-425

Werner EE, Hall DJ (1988) Ontogenetic habitat shifts in bluegill: the foraging rate-predation risk trade-off. Ecology 69:1540-1548

Winemiller KO, Pianka ER (1990) Organization in natural assemblages of desert lizards and tropical fish. Ecol Monogr 60:27-55

Submitted: November 3, 1999; Accepted: March 8, 2000

Proofs received from author(s): July 28, 2000 